\title{
Validation of the interview-based life-space assessment in institutionalized settings (LSA-IS) for older persons with and without cognitive impairment
}

Klaus Hauer ${ }^{1,2^{*}}$ (D) Phoebe Ullrich ${ }^{1}$, Patrick Heldmann ${ }^{3}$, Saskia Hummel ${ }^{4}$, Jürgen M. Bauer ${ }^{1,2}$ and Christian Werner ${ }^{2}$

\begin{abstract}
Background: Self-reported life-space assessment methods so far focus on community-dwelling persons, with a lack of validated assessment methods for institutionalized settings. This study evaluated construct validity, test-retest reliability, sensitivity to change, and feasibility of a new Life-Space Assessment for Institutionalized Settings (LSA-IS) in geriatric patients.
\end{abstract}

Methods: Psychometric properties of the LSA-IS in 119 hospitalized geriatric patients ( $83.0 \pm 6.2$ years) with and without cognitive impairment (CI) [Mini-Mental State Examination: $22.4 \pm 4.9$ scores] were evaluated within a comprehensive validation design. For the total group and subgroups according to cognitive status, construct validity was assessed by calculating Spearman's rank correlation coefficients (rho) with established construct variables, test-retest reliability by intra-class correlation coefficients (ICCS), sensitivity to change by standardized response means (SRMs) calculated for effects of early ward-based rehabilitation during hospital stay.

Results: The LSA-IS (total score) demonstrated good test-retest reliability (ICC =.704), and large sensitivity to change (SRM = 806), while construct validity was small to high indicated by significant correlations of the LSA-IS to construct variables (rho $=.208-716)$, depending on relative construct association. On average results of LSA-IS subscores confirmed results of the total score. Subgroups according to cognitive status did not differ for most analyzed variables. A completion rate of $100 \%$ and a completion time of $3.2 \pm 1.2$ min documented excellent feasibility.

Conclusions: The interview-based LSA-IS has proven to be valid, reliable, sensitive, and feasible in hospitalized, multi-morbid, geriatric patients with and without $\mathrm{Cl}$ documenting good psychometric properties for institutionalized settings.

Trial registration: DRKS00016028

Keywords: Assessment, Clinical trial methods, Cognitive impairment, Life-space mobility, Measurement, Exercise, Physical activity, Validation

* Correspondence: khauer@bethanien-heidelberg.de

${ }^{1}$ AGAPLESION Bethanien Hospital Heidelberg/Geriatric Centre of the

University of Heidelberg, Rohrbacher Str. 149, 69126 Heidelberg, Germany

${ }^{2}$ Center of Geriatric Medicine, Heidelberg University, Heidelberg, Germany

Full list of author information is available at the end of the article

C The Author(s). 2020 Open Access This article is licensed under a Creative Commons Attribution 4.0 International License, which permits use, sharing, adaptation, distribution and reproduction in any medium or format, as long as you give appropriate credit to the original author(s) and the source, provide a link to the Creative Commons licence, and indicate if changes were made. The images or other third party material in this article are included in the article's Creative Commons licence, unless indicated otherwise in a credit line to the material. If material is not included in the article's Creative Commons licence and your intended use is not permitted by statutory regulation or exceeds the permitted use, you will need to obtain permission directly from the copyright holder. To view a copy of this licence, visit http://creativecommons.org/licenses/by/4.0/. The Creative Commons Public Domain Dedication waiver (http://creativecommons.org/publicdomain/zero/1.0/) applies to the data made available in this article, unless otherwise stated in a credit line to the data. 


\section{Background}

Mobility in institutionalized settings is severely restricted with the consequence of a highly sedentary behavior of older patients during hospital stay or nursing home residents spending most of their time lying or sitting $[1,2]$. This immobility is associated with relevant, negative consequences such as drastic functional decline and muscle loss [3, 4], and higher risk for nursing home placement and mortality following hospitalization [5]. While mobility in community-dwelling older persons is influenced by a large number of individual as well as societal factors [6, 7], in institutionalized persons some additional factors become specifically relevant [8]. Such factors with influence on mobility status during hospitalization cover patient-related (illness severity, comorbid conditions), treatment-related (bed-rest required, hospital devices such as catheters, restraints), attitudinal (attitudes towards mobility, expectations of hospital stay), and institutional aspects (nursing to patient ratio, availability of equipment) [9]. Institutions such as hospitals or nursing homes also have an overwhelming organizational influence by their treatment routines or social activities (e.g. timing/ location of meals) [10].

Among the vulnerable, multi-morbid persons in institutionalized settings, persons with CI stand out, as they show a decreased health status compared to their nonimpaired peers $[11,12]$, relevant for their health prognosis but also for health assessments. To address the specific limitations and resources of this vulnerable group, it is mandatory to specifically develop and validate assessment methods in this population [13-15].

To better understand health trajectories while being institutionalized, a large number of established assessments and diagnostic procedures have been established also including functional status or motor performance. Surprisingly the concept of life-space mobility (LSM) has not made it yet into these diagnostic routines despite its' unique ability to cover mobility-related quality of life and its' potential role as a "biomarker" of health status, documenting the individual habitual physical activity range in contrast to highly standardized testing routines. For assessment purposes the LSM concept offers chances as well as challenges as it is determined by various domains related to the individual status as well as social interaction to others $[7,16]$.

A number of life-space assessment methods have been developed and validated for use in community dwelling persons such as the "Life-Space Diary" [17], the "LifeSpace Questionnaire" [18], the "University of Alabama at Birmingham - Life-Space Assessment" (UAB-LSA) [16], the "Life-Space Assessment in Persons with cognitive impairment" (LSA-CI) [14], and the "Life-Space mobility at home assessment" [19]. However, different validation approaches have been used for these life-space measures.
Construct validity was analyzed in all validation studies, but the comprehensiveness of constructs used differed substantially. Only one study selected variables based on a comprehensive theoretical, multi-domain framework on mobility [14], while literature-based constructs including variables of two or three domains as identified in previous comparable research $[16,18]$ or measures with strict focus on one domain (physical function) $[17,19]$ have been used in other studies. Reliability was tested in terms of intrarater reliability [19], and test-retest reliability [14, 16, 18]. Feasibility was analyzed in only few studies, with one study presenting a comprehensive documentation of duration of assessment, completeness of reports, and floor/ceiling effects [14] and other studies reporting on potential ceiling effects [16] or completeness [17]. Sensitivity to change has been the least analyzed psychometric property performed in two studies $[14,16]$.

The only LSM assessment (The "Nursing Home LifeSpace Diameter", NHLSD) which could be identified for an institutionalized setting [20], performed a validation with reliability and restricted construct validity with functional-social variables, but not an evaluation of comprehensive construct validity, feasibility, or sensitivity to change. Level of personal support represents an option for data assessment but was not included in presented data of the validation. The NHSLD was designed to be nurse-administered which may differ from a patient perspective with additional burden to nurses. As with other established mobility assessment methods, the evaluation tool was not specifically tailored and validated for use in multi-morbid, vulnerable populations such as persons with cognitive impairment (CI), with relevant potential limitations for self-report, although such vulnerable persons represent the majority in a large number of institutionalized settings. The fixed time frame of 2 weeks of the NHLSD is not feasible at least in hospital settings with varying duration of hospital stay, most often less than 2 weeks.

The objective of the present study therefore was to comprehensively validate a new, detailed, interviewbased LSM assessment, specifically developed for institutionalized persons with and without $\mathrm{CI}$ including construct validity, test-retest reliability, sensitivity to change, and feasibility in hospitalized geriatric patients including subsamples according to cognitive status.

\section{Methods}

\section{Study design}

The present study follows a comprehensive validation design (see Additional file 3) using secondary data from a prospective, longitudinal cohort study examining physical activity behaviour and mobility of geriatric patients with and without $\mathrm{CI}$ during hospitalization (trial registration number: DRKS00016028). The study was performed 
according to the Helsinki Declaration and was approved by the ethics committee of the Medical Department of the University of Heidelberg (S-709/2018).

\section{Study sample}

Participants were consecutively recruited from acute medical wards of a geriatric hospital. Individuals receiving complex early geriatric rehabilitation treatment according to the German hospital payment system (German Diagnosis-Related Groups) were included by the following inclusion criteria: age $\geq 65$ years, Mini-Mental State Examination (MMSE [21]) score $\geq 10$, ability to walk at least 4 $\mathrm{m}$ with or without walking aid, no terminal illness, no severe functional, sensorial or behavioral restrictions, which did not allow study participation or assessment, no delirium (Confusion Assessment Method [22]), no uncontrolled infection, adequate language level, and written informed consent (obtained from patients or their legal representatives) within $72 \mathrm{~h}$ after admission.

\section{Descriptive measures}

Descriptive data were collected at baseline from patient charts after hospital admission to describe the sample and to analyze construct validity. Trained interviewers assessed measures for health status (weight and height to calculate Body Mass Index (BMI), number of medication, frailty status (Clinical Frailty Scale, CFS [23], falls in the previous year [24], pain (Present Pain Intensity scale, 6 points, PPI [25]), cognitive status (MMSE), and psychological status (health-related quality of life (EuroQol-questionnaire, EQ5D-3L [26]), apathetic symptoms (Apathy Evaluation Scale- Clinical version, AES-C [27]), and concerns about falling (Short Falls Efficacy Scale-International, 7-item version, Short-FES-I [28, 29]). Motor-functional status was assessed by the Activities of Daily Living (ADL, BarthelIndex [30]), the Short Physical Performance Battery (SPPB [31]), and gait speed from the SPPB. Physical activity (reported as number of steps) was assessed for a $48 \mathrm{~h}$ period using the uSense sensor, which has been validated in multi-morbid, geriatric patients [32].

\section{Clinical intervention}

The "complex early geriatric rehabilitation" as analyzed in the present study represents an established rehabilitation routine/pathway to prevent loss of function during in-hospital, acute medical treatment. It was developed as a multidisciplinary, geriatric rehabilitation program including at least two of the following four domains: physiotherapy, occupational therapy, speech and language therapy, and psychology (Operation and Procedure Code version 2018, German Institute of Medical Documentation and Information), (https://www.dimdi.de/static/de/klassifikationen/ops/kodesuche/opshtml2020/).

\section{Life-space assessment}

The Life-Space Assessment in Institutionalized Settings (LSA-IS) is a newly developed, interview-based instrument tailored for the specific target setting to assess LSM by the spatial extent of movement, the frequency of movement, and the level of assistance for movement within institutions during the previous day. The short time frame allows to evaluate trajectories of LSM in institutionalized settings, considering the special needs of persons with acute or chronic medical events and/or CI as well as institution-/organization-based restrictions in LSM. The LSA-IS' basic structure is defined by lifespace zones within a typical institutionalized setting ranging from a person's own room to outside the facility (e.g. garden of nursing home and beyond the outdoor area of the facility (e.g., public area, neighborhood) to document also higher functioning mobility levels (outdoor), which are still preserved in a minority of institutionalized persons.

The LSA-IS also documents the independence of mobility (i.e., without any support, with equipment or personal support) by a detailed qualitative and quantitative approach. Such a semi-qualitative approach seems mandatory given the low functional status, the extraordinary high risk of falling, and the high implementation level of equipment-, or staff- supported mobility in institutionalized settings such as geriatric hospitals or nursing homes.

The interview procedure of the LSA-IS includes an interview-based and strictly standardized face-to-face questionnaire with a clear focus on the subjective selfreport of participants rather than proxy reports. Assessment strategies of the LSA-IS were thus optimized to gain correct and complete information including multimorbid persons with and without CI. The interview is based on an informal conversational approach to prevent fear of failure in comprehension and recall by precise and structured questions and response options, reduction of recall period, clear structure of the observation period by referring to daily routines and landmark events such as meals, doctoral visits, or therapies, or special events such as external visits, and a summary of the given information for immediate review of reports. This approach is based on previous research to validly assess LSM [14] and physical activity for a short recall period $(24 \mathrm{~h})$ in older persons with CI [13, 33, 34].

The LSA-IS is structured by three criteria: A) spatial extent of movement, classified into five hierarchically structured, concentric zones (level $1=$ own room, level $2=$ within the ward, level $3=$ within the facility, level $4=$ immediate outdoor area of the facility, level $5=$ beyond the area of the facility); B) frequency of movement ( $1=$ $1 \times$ per day, $2=2-3 \times$ per day, $3=4-5 \times$ per day, $4=>$ $5 \times$ per day); and $\mathrm{C})$ : independence of movement $(1=$ 
with personal support, $1.5=$ with equipment, $2=$ without any support).

A score for each life-space zone is calculated by multiplying values for the zone, frequency and independence. Each life-space zone is added to a LSA-IS-T total score, with the lowest score of 0 indicating total immobility (bed-bound) and the maximum score of 120 indicating independent mobility beyond the area of the facility at least six times at the relevant day. In addition, three LSA sub-scores can be determined for the maximal life-space zone achieved (1) with equipment or personal assistance if needed (LSA-IS-M, range 0-5), (2) with equipment, if needed, but without personal assistance (LSA-IS-E, range 0-5), and (3) independently without any assistance (LSA-IS-I, range 0-5) $[14,16]$. For details of the test proceeding see manual attached in supplements (Additional files 1 and 2).

\section{Assessment of measurement properties}

The analysis of construct validity, test-retest reliability, and sensitivity to change was performed for the total group and subgroups according to cognitive status as a most relevant criteria for rehab prognosis also considering the high incidence of $\mathrm{CI}$ in institutionalized settings. Study participants with MMSE scores < 24 (range: 10-23) were considered cognitively impaired and participants with scores $\geq 24$ (range: $24-30$ ) cognitively intact [21].

\section{Construct validity}

Assessment of construct validity was conducted after hospital admission. Items for construct validity were selected according to previous, directly comparable validation studies for life-space assessment for the UAB-LSA [16], the LSA-CI [14] and the NHLSD [20], guided by and categorized according to the comprehensive and wellestablished mobility model by Webber [6]. Correlations between the LSA-IS scores at baseline with demographic variables (age, gender), measures for health status (BMI, number of medication, frailty status (CFS, falls, pain), cognitive status (MMSE), psychological status (EQ-5D, AESC, FES-I,), motor - functional status (ADL Barthel Index, SPPB, gait speed), and physical activity (assessed by uSense and reported as number of steps, duration of lying, activity, and gait) were calculated.

\section{Test-retest-reliability}

The LSA-IS assessment was conducted on two consecutive days with general assessments being performed by the same trained interviewer to exclude inter-rater variability.

\section{Sensitivity to change}

Sensitivity to change was examined in all participants tested at admission and at the end of the hospital stay immediately before discharge for effects of the complex early geriatric rehabilitation on LSM.

\section{Feasibility}

Completion rate and completion time for the questionnaire were documented at baseline to determine feasibility. In addition, LSA-IS scores at baseline were checked for floor and ceiling effects, which were considered present when more than $15 \%$ of the individuals achieve the lowest or highest score [35].

\section{Statistical analysis}

Descriptive data were presented as frequencies and percentages for categorical variables, and means and standard deviations or medians and ranges for continuous variables as appropriate. Comparison with respect to descriptive characteristics between groups according to cognitive status was conducted using $t$-tests and MannWhitney- $U$ tests as appropriate.

Spearman's rank-order and point-biserial correlation coefficients between LSA-IS scores and a comprehensive set of associated factors selected in accordance with a theoretical framework and existing research evidence were calculated to assess construct validity. Correlation coefficients $(r)$ were interpreted as small $(r=0.1-0.3)$, moderate $(r=0.3-0.5)$, or high $(r>0.5)$ [36].

Independent from formal cut-off criteria, we hypothesized a priori low to moderate associations of the LSA-IS scores with health-related, psychological and cognitive variables and moderate to high correlations with motor-functional variables and variables documenting physical activity behavior.

Intra-class correlation coefficients (ICC) with 95\% confidence intervals for the LSA-IS total score and each subscore were used to analyze test-retest reliability. ICCs were interpreted as poor $(<0.4)$, fair to good $(\geq 0.4 \leq 0.75)$, and excellent $(>0.75)$ [37]. Sensitivity to change was assessed using paired $t$-tests to test for significant withingroup differences between assessments at admission and immediately before discharge and standardized response means (SRMs) to quantify the magnitude of changes. SRMs were calculated as the difference in mean change scores divided by the $S D$ of the change score [38]. SRMs were adjusted for the size of correlation coefficients between the baseline and post-intervention scores [39] to use Cohen's thresholds for effect sizes (trivial $<0.2$, small $\geq 0.2<0.5$, moderate $\geq 0.5<0.8$, and large $\geq 0.8$ ) [36]. The level of significance was set to $p<0.05$. All statistical analyses were performed using the Software IBM SPSS Statistics Version 23 for Windows (IBM Corp., NY, USA).

\section{Results}

\section{Participants' characteristics}

The study sample included 119 multi-morbid $(10.2 \pm 4.3$ medications at admission), older (mean age $83.0 \pm 6.2$ 
years) persons with CI (MMSE score: 23 (10-30) points) and motor impairment (SPPB score: $4(0-11)$ points). Apart from the classification criteria (MMSE score $<24$ vs. $\geq 24$ ), subsamples with and without CI differed with respect to frailty-, functional-, motor-, and psychological status (CFS, ADL, SPPB AES-C) indicating a reduced status in persons with $\mathrm{CI}$ but more apathetic symptoms in the group without CI (Table 1).

\section{Description of life-space mobility}

The mean total score for the LSA-IS of $12.7 \pm 9.0$ (range: 0-48 points) indicated a largely restricted LSM for the total group. Restriction of life-space was also confirmed for all sub-scores such as the LSA-IS-M for maximal life-space with technical and personal support: $(2.2 \pm$ $1.0)$, the LSA-IS-E as achieved with supportive devices $(1.7 \pm 1.2)$, and the independent life-space (LSA-IS-I), achieved without human or technical assistance (0.4 \pm 1.0). Results differed significantly between persons with and without CI for the total score and the LSA-IS-E, but not for the LSA-IS-M and the LSA-IS-I (Table 2).

\section{Construct validity}

In the total sample, the LSA-IS-T (total score) showed significant moderate associations to most variables documenting demographic and health status (age, BMI, number of medication, frailty status), cognitive status (MMSE), or psychosocial status (FES-I, EQ-5D, AES-C). Other variables such as gender, history of falls, and pain were not associated with LSA-IS (Table 3). Motor-functional status and activity behavior stood out with significant associations in all parameters especially so for variables related to activity behavior indicated by higher associations to LSM.

On average a trend for lower associations is visible for the sub-score LSA-IS-I (independent score) as compared to the total score and other sub-scores throughout all samples.

When classified into persons with intact and impaired cognition, results of the total group were confirmed for most associations, while descriptive variables and

Table 1 Participant characteristics for the total study sample $(n=119)$, and subgroups according to cognitive status

\begin{tabular}{|c|c|c|c|c|}
\hline Characteristics & $\begin{array}{l}\text { (Mean (SD)/ } n(\%) / \text { Median (range) } \\
\text { Total group } n=119 \text { ) }\end{array}$ & Non-Cl (MMSE $\geq 24) n=57$ & $\mathrm{Cl}(\mathrm{MMSE}<24) n=62$ & $P$-value* \\
\hline \multicolumn{5}{|l|}{ Demographic factors } \\
\hline Age, years & $82.95(6.20)$ & $82.49(6.54)$ & $83.37(5.89)$ & .488 \\
\hline Gender, female, n (\%) & $73(63.5 \%)$ & $38(66.7 \%)$ & $38(61.3 \%)$ & .546 \\
\hline \multicolumn{5}{|l|}{ Health status } \\
\hline $\mathrm{BMI}^{\mathrm{a}}$ & $26.24(13-48)$ & $26.33(16.98-48.04)$ & $25.87(13.77-37.42)$ & .480 \\
\hline Medications, number & $10.22(4.28)$ & $10.07(4.29)$ & $10.40(4.26)$ & .773 \\
\hline CFS, score ${ }^{c}$ & $6(3-8)$ & $6(3-7)$ & $6(3-8)$ & .012 \\
\hline PPI, score & $0(0-5)$ & $0(0-5)$ & $0(0-4)$ & .501 \\
\hline No. of falls in the previous year ${ }^{b}$ & $1(0-4)$ & $1(0-2)$ & $1(0-4)$ & .463 \\
\hline \multicolumn{5}{|l|}{ Cognitive status } \\
\hline MMSE, score & $23(10-30)$ & $27(24-30)$ & $19(10-23)$ & $<.001$ \\
\hline \multicolumn{5}{|l|}{ Psychosocial status } \\
\hline Short FES-I, score ${ }^{b}$ & $11(6-26)$ & $11.5(6-25)$ & $10.5(7-26)$ & .514 \\
\hline EQ-5D score & $0.70(0.96-1.00)$ & $0.79(0.06-1.00)$ & $0.64(0.06-1.00)$ & .237 \\
\hline AES-C, score ${ }^{b}$ & $25(5-35)$ & $26(6-35)$ & $22(5-35)$ & .017 \\
\hline \multicolumn{5}{|l|}{ Motor-functional status } \\
\hline ADL Barthel score ${ }^{c}$ & $75(5-100)$ & $80(25-100)$ & $65(5-100)$ & .009 \\
\hline SPPB, score ${ }^{a}$ & $4(0-11)$ & $5(0-11)$ & $3(0-10)$ & .026 \\
\hline Gait velocity $(\mathrm{s})^{\mathrm{d}}$ & $7.63(4.75)$ & $7.13(4.74)$ & $8.15(4.76)$ & .300 \\
\hline \multicolumn{5}{|l|}{ Physical activity } \\
\hline PA (mean number of steps per day) & $704(0-7095)$ & $813(1.5-6772)$ & $690(0-7095)$ & .293 \\
\hline \multicolumn{5}{|c|}{$\begin{array}{l}\text { Presented are patient characteristics for the study sample description for the total group and according to cognitive status. Total sample included } 119 \\
\text { participants, however, single measures are lacking for some individuals, including }{ }^{\mathrm{a} n} n=110 \text { participants, }{ }^{\mathrm{b}} n=112 \text { participants, }{ }^{\mathrm{c}} n=113 \text { participants, }{ }^{\mathrm{d}} n=94 \\
\text { participants. }{ }^{*} p \text {-values are given for Mann-Whitney } U \text { tests and } t \text {-tests as appropriate } \\
\text { Abbreviations: AES-C Apathy Evaluation Scale - Clinical version, BMI Body Mass Index, CFS Clinical Frailty Scale, MMSE Mini-Mental State Examination, } P P I \text { Present } \\
\text { Pain Intensity Scale, SPPB Short-Physical-Performance-Battery, Short FES-I Short Falls Efficacy Scale-International, 7-item version, VRS Verbal rating scale, EQ-5D } \\
\text { European health-related quality of life questionnaire (EuroQol-questionnaire, EQ-5D-3L), } n \text { Numbers, CI Cognitive impairment, SD Standard deviation, } m / s \text { Meters } \\
\text { per second, PA Physical activity }\end{array}$} \\
\hline
\end{tabular}


Table 2 Baseline LSA status for the LSA-IS composite score and sub-scores

\begin{tabular}{|c|c|c|c|c|}
\hline \multirow[t]{2}{*}{ LSA-Variables } & $\begin{array}{l}\text { Total group } \\
n=117^{\mathrm{a}}\end{array}$ & $\begin{array}{l}\text { Non-Cl } \\
n=57\end{array}$ & $\begin{array}{l}\mathrm{Cl} \\
n=60\end{array}$ & \multirow[t]{2}{*}{$\begin{array}{l}P \text { - } \\
\text { value } \\
* *\end{array}$} \\
\hline & Mean (SD) & Mean (SD) & Mean (SD) & \\
\hline LSA-IS-T total score & $12.72(9.00)$ & $14.94(10.34)$ & $10.62(6.96)$ & .035 \\
\hline LSA-IS-M maximal score & $2.17(.096)$ & $2.35(1.04)$ & $2.00(0.84)$ & .084 \\
\hline LSA-IS-E equipment-assisted score & $1.74(1.16)$ & $2.05(1.16)$ & $1.45(1.10)$ & .008 \\
\hline LSA-IS-I independent score & $0.44(1.99)$ & $0.51(1.14)$ & $0.37(0.86)$ & .546 \\
\hline
\end{tabular}

Presented are results for the total group and sub-groups according to cognitive status

Abbreviations: LSA-IS Life-space assessment for institutionalized settings, $-T$ Total score, $-M$ Maximal life-space, E Equipment assisted life-space, I Independent life-space

${ }^{* *} p$-values are given for Mann Whitney $U$ tests for differences between persons without cognitive impairment (Non-Cl; $n=57$ ), and persons with cognitive impairment $(\mathrm{Cl} ; n=60)$ at baseline. ${ }^{a} n=2$ were excluded, as these persons were transferred for diagnostic reasons during the relevant time period

variables related to health status were less associated. Some variables differed as age, cognitive status, and duration of lying were only significantly associated to LSM in the group of cognitively intact persons, while the number of medications was only significantly correlated in the group of persons with CI (Table 3).

\section{Test-retest reliability}

ICCs between the two LSA-IS assessments indicated fair to excellent test-retest reliability for all LSA-IS scores, with ICCs ranging from .412-.799 except for 1 result (LSA-IS-M, .285, subgroup with CI). Results for testretest reliability were comparable in both groups according to cognitive status. Within LSA-IS scores, the LSAIS-M (maximal) score presents with an on average lower reliability as compared to all other scores while the LSAIS-I (independent) stood out with excellent results in all samples (Table 4).

\section{Sensitivity to change}

All LSA-IS scores differed over the treatment period $(p \leq .001)$, indicating a global sensitivity to change of the assessment method. Improvements of LSM as documented by SRMs during the hospital stay were found across all LSA-IS scores for the total group, with the highest SRM for the LSA-IS-T (.806), while LSA-IS-I subscores reached lower SRMs (.326-.667). The two groups according to cognitive status achieved comparable results with the highest value for the total score (cognitively intact persons: .812, persons with CI: .833), and values for subscores ranging from .383-.812 for persons with intact cognition and .269-.833 for persons with CI. Across all samples, the LSA-IS-I (independent score) showed the least responsiveness during hospital stay, while results of the total score achieved SRMs $>.800$ in all samples indicating large responsiveness (Table 5).

\section{Feasibility}

No participant objected to the assessment procedure and data documentation was comprehensive, with no missing responses for any LSA-IS item (100\% completion rate). Mean completion time to assess the LSA-IS was brief with $3.2 \pm 1.2 \mathrm{~min}$ (range 1-11) and not significantly different between subgroups by cognitive status (CI: $3.0 \pm 0.9$ vs. non-CI: $3.4 \pm 1.5$ ). For the total score no relevant ceiling (no participant) or floor effects $(n=3$ (2.6\%) occurred [35]. None of the sub-scores presented ceiling effects, however, the sub-scores LSA-IS-E and the LSA-IS-I showed relevant floor effects (LSA-IS-E: 19.3\%; LSA-IS-I: $79.0 \%$ ) in this population of vulnerable patients during hospital stay.

\section{Discussion}

The LSA-IS (total score) demonstrated good test-retest reliability, high sensitivity to change, while construct validity was appropriate depending on relative construct association as hypothesized. Results of LSA-IS sub-scores confirmed most results of the total score, while results of persons with and without CI did not differ for most analyzed variables. A very high completion rate and a brief completion time indicated excellent feasibility for use in research or clinical routines.

\section{Construct validity}

For construct validation we used construct variables out of different domains to allow a validation within a comprehensive Life Space Mobility model. We assumed different levels of associations for different domains based on their content association to LSM based on results of previous comparable studies $[14,16,32]$ and in line with the comprehensive and well-established mobility model by Webber [6]. Present results of the construct validation fitted well with these a priori assumptions, indicating good construct validity of the assessment. The LSAIS total score showed significant, moderate associations to most variables documenting demographic-, health-, cognitive-, and psychosocial status representing more "distant" domains to the LSA representing a behavioral activity measure As hypothesized, motor-functional status and activity behavior stood out with significant, 


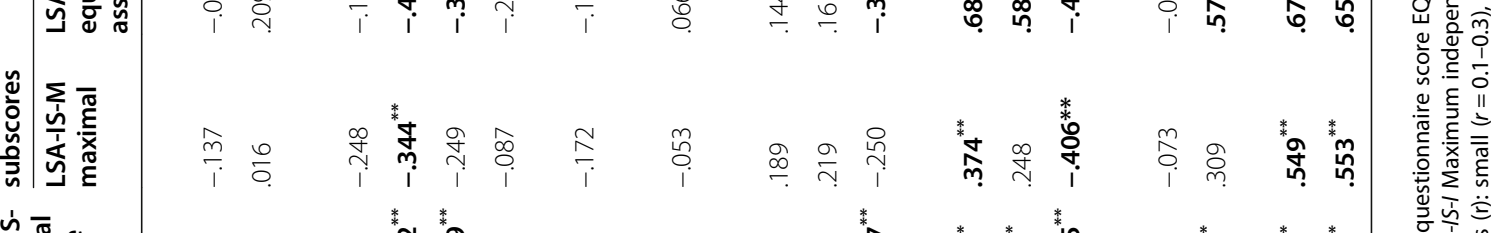

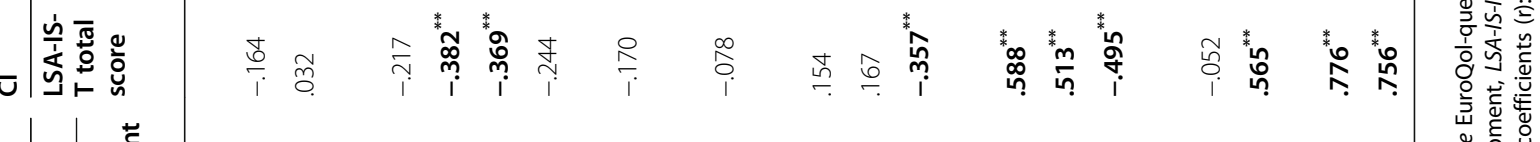

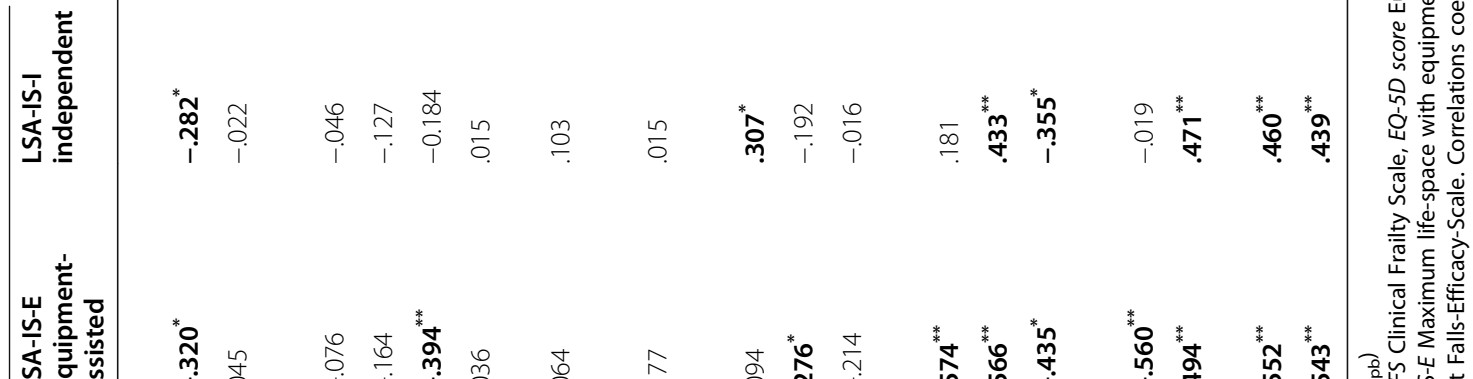

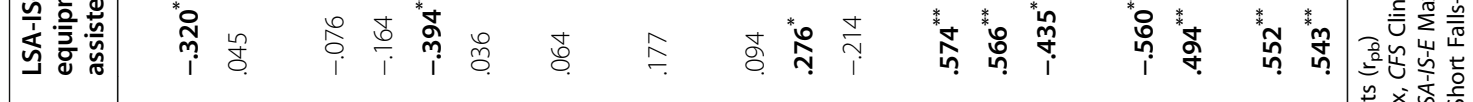

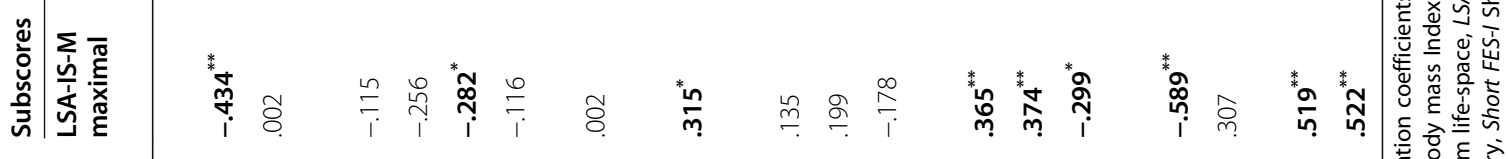

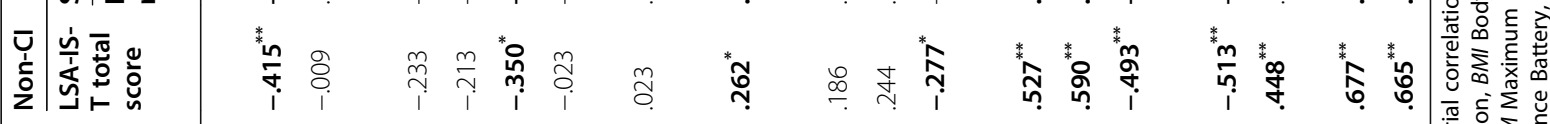

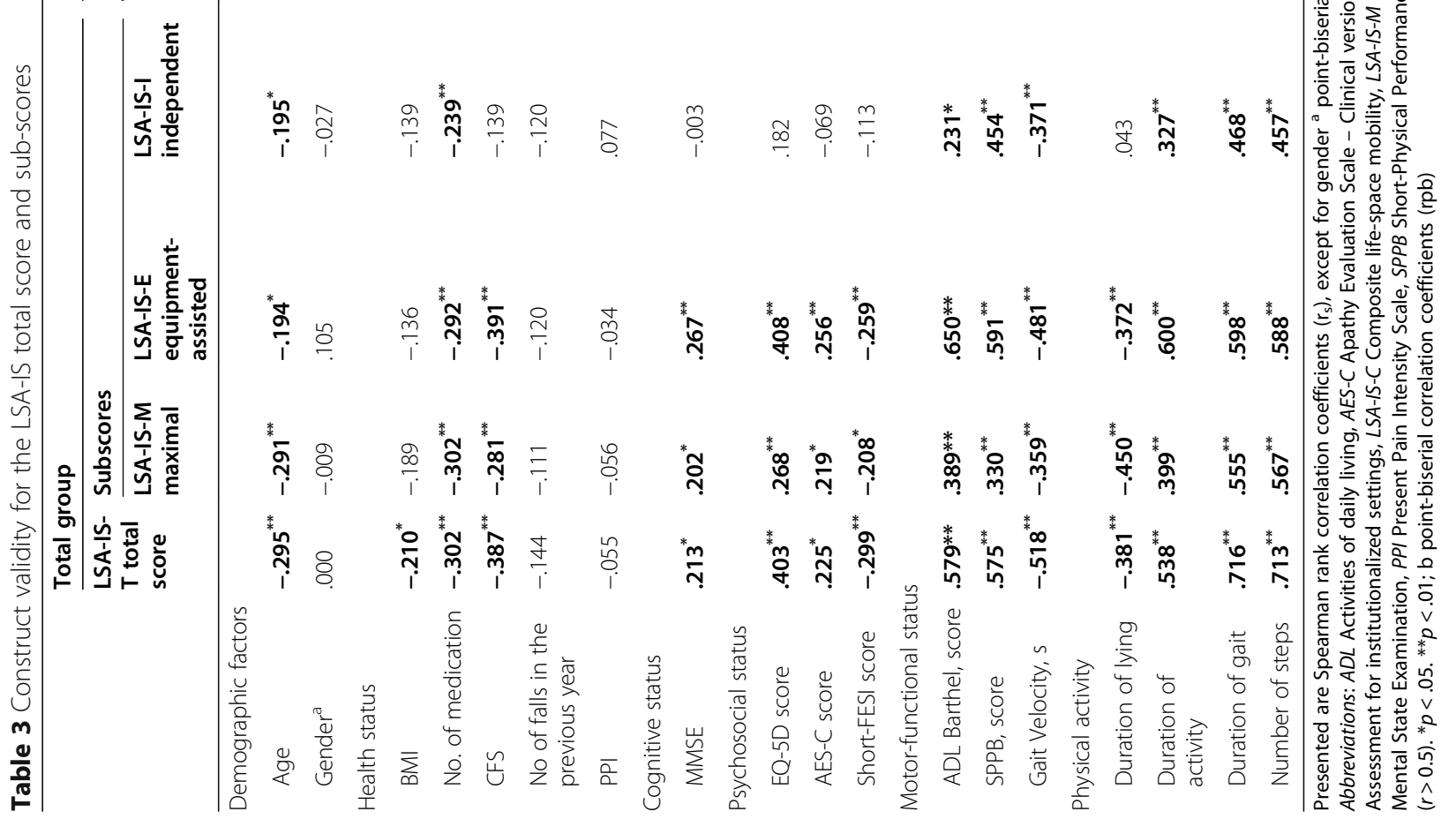


Table 4 Test - retest reliability for total group and subgroups

\begin{tabular}{|c|c|c|c|c|}
\hline Variable & \multicolumn{3}{|l|}{ Mean (SD) } & $95 \% \mathrm{Cl}$ \\
\hline \multicolumn{5}{|c|}{ Total group $(n=76)$} \\
\hline LSA-IS-T & $18.42(10.21)$ & $19.20(10.91)$ & .704 & $.570-.801$ \\
\hline \multicolumn{5}{|l|}{ Subscores } \\
\hline LSA-IS-M & $2.74(0.93)$ & $2.79(0.94)$ & .412 & $.208-.582$ \\
\hline LSA-IS-E & $2.32(1.16)$ & $2.34(1.23)$ & .741 & $.620-.827$ \\
\hline LSA-IS-I & $0.64(1.10)$ & $0.80(1.34)$ & .799 & $.701-.868$ \\
\hline \multicolumn{5}{|c|}{ Non-CI/Subsample with intact cognition $(n=36)$} \\
\hline LSA-IS-T & $19.29(11.29)$ & $21.72(12.50)$ & .715 & $.511-.843$ \\
\hline \multicolumn{5}{|l|}{ Subscores } \\
\hline LSA-IS-M & $2.81(0.92)$ & $2.86(0.96)$ & .558 & $.288-.747$ \\
\hline LSA-IS-E & $2.56(1.06)$ & $2.67(1.04)$ & 671 & $.445-.817$ \\
\hline LSA-IS-I & $0.69(1.17)$ & $0.83(1.34)$ & .798 & $.641-.891$ \\
\hline \multicolumn{5}{|c|}{$\mathrm{Cl} /$ Subsample with impaired cognition $(n=40)$} \\
\hline LSA-IS-T & $17.64(9.19)$ & $16.93(8.80)$ & .676 & $.467-.814$ \\
\hline \multicolumn{5}{|l|}{ Subscores } \\
\hline LSA-IS-M & $2.68(0.94)$ & $2.73(0.93)$ & .285 & $-.023-.544$ \\
\hline LSA-IS-E & $2.10(1.22)$ & $2.05(1.32)$ & .766 & $.602-.869$ \\
\hline LSA-IS-I & $0.60(1.06)$ & $0.78(1.35)$ & .805 & $.662-.892$ \\
\hline
\end{tabular}

Presented are results of test-re test reliability for the total group and subscores according to cognitive status

Abbreviations: Cl Confidence interval, LSA-IS Life-Space Assessment for institutionalized settings, LSA-IS-T Total life-space mobility, LSA-IS-M Maximum life-space, LSA-IS-E Maximum life-space with equipment, LSA-IS-I Maximum independent life-space; ICCs were interpreted as poor $(<0.4)$, fair to good $(\geq$ $0.4 \leq 0.75)$, and excellent $(>0.75)$

higher associations for all construct parameters with all of them representing a common motor domain.

Two out of three sub-scores (LSA-IS-M, LSA-IS-E) followed the results for the total score, while a trend for lower associations was visible for the sub-score LSA-IS-I (independent score). We assume the weaker association to be caused by the lower incidence of independent, nonsupported mobility in this multi-morbid, vulnerable sample during acute, ward-based medical care with a higher number of participants with low levels of LSA-IS-I.

Results of the construct validation also indicate that achieved good results were not different between subgroups according to cognitive status for most variables, indicating good validity also for persons with moderate to more advanced stages of $\mathrm{CI}$, representing the majority of patients in geriatric hospitals as well as other institutionalized settings.

\section{Test-retest reliability}

Test-retest reliability was good to excellent in the total score as well as two out of three sub-scores, indicating highly stable results for the LSA-IS in general. Results are in line with a trend for lower reliability as compared to previous validation studies for community dwelling older persons documented by ICCs $[14,16]$. The lower test-re-test reliability for the sub-score maximal lifespace is in line with a trend for lower reliability as compared to a previous validation study for community dwelling older persons documented by ICCs [16] and may be caused by the fact that maximal life-space, including outer ranges of mobility such as cafeteria visits or even outdoor visits beyond into the neighboring surrounding (e.g. hospital garden), are more infrequent and random in vulnerable, institutionalized persons. Occurrence of such events heavily depend on external support and are therefore less reliable when tested in a short period of time, but do not necessarily indicate a lower biometrical quality of the evaluation method. However, the low reliability of this sub-score may indicate a limitation for this specific hospital setting.

\section{Sensitivity to change}

All LSA-IS scores significantly increased during the relatively short assessment period within an intervention (early ward-based rehab) which was not specifically tailored to achieve LSM changes, indicating a global sensitivity to change of the assessment method. Specific modification of the LSA-IS, such as framing of the observation period, supported the good responsibility. Apart from supporting recall in persons with memory deficits, relevant for all institutional settings, the short observation period as used for the LSA-IS, represented a precondition to document sensitivity to change in hospital or rehab settings within the given limited time frame of therapeutic interventions.

Other life-space assessment validation did predominantly not include this biometrical measure which is highly relevant to document efficacy of interventions in research or clinical routines. The two comparable studies used different statistical strategies. While Baker used a dichotomized descriptive analysis without statistical analysis and a longitudinal, observational design demonstrating adequate responsiveness [16], Ullrich reported comparable results to the present study for effects of an RCT on activity promotion to document good sensitivity to change [14].

In the present study sensitivity to change as documented by SRMs was large for the main total score summarizing all changes for all independence levels and areas of mobility. Moderate effects for the sub-scores LSA-IS-M and LSA-IS-E documented effects of routine hospital-based rehab, leading to relevant changes to extent mobility by using technical or personal support. The sub-score with the least responsiveness (LSA-IS-I) was relevant for only a minority of high functioning persons not using such support, which is almost mandatory for ambulation of multi-morbid persons within hospitals [40]. The somewhat lesser responsiveness may therefore 
Table 5 Sensitivity to change of the LSA-IS total score and sub-scores

\begin{tabular}{|c|c|c|c|c|c|}
\hline Variables & $\begin{array}{l}\text { Test at admission } \\
\text { Mean (SD) }\end{array}$ & Test at discharge & $\begin{array}{l}P \text { - } \\
\text { value* }\end{array}$ & SRM & $\begin{array}{l}\text { Adjusted } \\
\text { SRM }\end{array}$ \\
\hline \multicolumn{6}{|c|}{ Total sample $(n=69)$} \\
\hline LSA-IS-T & $12.43(8.82)$ & $19.17(11.12)$ & $<.001$ & 0.696 & 0.806 \\
\hline \multicolumn{6}{|l|}{ Subscores } \\
\hline LSA-IS-M & $2.22(1.00)$ & $2.80(1.01)$ & $<.001$ & 0.545 & 0.667 \\
\hline LSA-IS-E & $1.68(1.14)$ & $2.29(1.21)$ & $<.001$ & 0.574 & 0.647 \\
\hline LSA-IS-I & $0.46(1.11)$ & $0.78(1.33)$ & $<.001$ & 0.292 & 0.326 \\
\hline \multicolumn{6}{|c|}{ Subsample with intact cognition $(n=33)$} \\
\hline LSA-IS-T & $14.20(9.62)$ & $21.89(12.77)$ & $<.001$ & 0.700 & 0.812 \\
\hline \multicolumn{6}{|l|}{ Subscores } \\
\hline LSA-IS-M & $2.30(0.98)$ & $2.91(1.01)$ & $<.001$ & 0.572 & 0.701 \\
\hline LSA-IS-E & $1.97(1.08)$ & $2.67(0.99)$ & $<.001$ & 0.648 & 0.786 \\
\hline LSA-IS-I & $0.55(1.23)$ & $0.94(1.41)$ & $<.001$ & 0.353 & 0.383 \\
\hline \multicolumn{6}{|c|}{ Subsample with cognitive impairment $(n=36)$} \\
\hline LSA-IS-T & $10.82(7.81)$ & $16.67(8.82)$ & $<.001$ & 0.701 & 0.833 \\
\hline \multicolumn{6}{|l|}{ Subscores } \\
\hline LSA-IS-M & $2.14(1.02)$ & $2.69(1.01)$ & $<.001$ & 0.514 & 0.631 \\
\hline LSA-IS-E & $1.42(1.16)$ & $1.94(1.31)$ & $<.001$ & 0.500 & 0.548 \\
\hline LSA-IS-I & $0.39(0.96)$ & $0.64(1.25)$ & .004 & 0.232 & 0.269 \\
\hline
\end{tabular}

Presented are results for sensitivity to change for effects of early rehabilitation during hospital stay

Abbreviations: SD Standard deviation, SRM Standardized response mean, LSA-IS Life-Space Assessment for institutionalized settings, LSA-IS-T Total life-space mobility, LSA-IS-M Maximum life-space, LSA-IS-E Maximum life-space with equipment, LSA-IS-I Maximum independent life-space; Adjusted SRMs are classified as < $0.2=$ trivial, $\geq 0.2<0.5=$ small, $\geq 0.5<0.8=$ moderate, $\geq 0.8=$ large

*difference between admission and discharge

rather be an indicator of the very low functional status of the study sample than a methodological limitation of the evaluation method. As with other biometrical domains in this study, no relevant differences were documented between subgroups according to cognitive status, indicating good responsiveness of the LSA-IS also in persons with CI. Results, as achieved in this study may mirror the special focus of the development of the LSA-IS on persons with CI, that require a specific approach due to their special needs $[13,14,41]$.

\section{Feasibility}

The 100\% completion rate with no missing responses documented an excellent feasibility of the LSA-IS even in multi-morbid, vulnerable persons during acute medical, ward-based treatment. The specific component of the questionnaire such as the interview-based interrogation, the interview technique tailored to the study sample including persons with moderate to more advanced stages of $\mathrm{CI}$, as in previous successful validation studies $[13,14]$ and the highly organized setting with restricted degrees of freedom for mobility following standardized routines, which are easy to recall and structure by interview, may have helped to achieve this extraordinary result. The LSA-IS completion time of $3.2 \mathrm{~min}$ is very brief allowing its use in research as well as clinical routines with only very little resources and no risk of overtaxation of interviewed persons.

As in comparable questionnaires [20] or sensor-based LSA [10], the LSA-IS includes categories extending beyond the institutions covering the clinically relevant transition from protected indoor to demanding outdoor activity.

In the present study floor effects occurred in two subscores with focus on equipment-assisted or independent life-space. In a clinical acute setting with multi-morbid, vulnerable persons, most of those not able to independently move without technical or personal support and with institutional activity restrictions to stay indoors, such a result is to be expected. On the other hand, as a logical consequence, the main total score and the sub-score including technical or personal support did not have such floor effects and none of the scores showed ceiling effects as documented in other LSM assessment validation studies which reported on this issue $[14,16]$. It is noteworthy that good feasibility could be achieved also in the group with moderate to more advanced stages of $\mathrm{CI}$, with specific limitations for a questionnaire-based assessment.

\section{Limitations}

Although the LSA-IS has been developed for generic use in comparable institutional settings, formally the present 
validation is focused on ward-based acute geriatric care and generalizability of its' psychometric properties will have to be additionally confirmed for other settings.

\section{Conclusions}

The results of this study demonstrate good validity, reliability, sensitivity to change, and feasibility of the newly developed LSA-IS in geriatric patients without and with moderate to advanced stages of $\mathrm{CI}$ during acute, inhospital medical treatment. Based on the high comparability of organizational structures and populations, we consider the use of the instrument feasible in other comparable institutionalized settings such as other inhouse medical care, rehabilitation centers, or in nursing homes settings.

\section{Supplementary Information}

The online version contains supplementary material available at https://doi. org/10.1186/s12877-020-01927-8.

Additional file 1. Life-Space Assessment in Institutionalized Settings (LSA-IS). (documentation form)

Additional file 2. Life-Space Assessment for Persons in institutionalized settings (LSA-IS) - User Manual.

Additional file 3. COSMIN Study Design checklist for Patient-reported outcome measurement instruments.

\section{Abbreviations}

AES-C: Apathy Evaluation Scale - Clinical version; BMI: Body Mass Index; CFS: Clinical Frailty Scale; Cl: Cognitive impairment; EQ-5D: European healthrelated quality of life questionnaire (EQ-5D-3L); LSA-Cl: Life-Space Assessment in Persons with cognitive impairment; LSA-IS: Life-Space Mobility in Institutionalized Settings; LSM: Life-space mobility; n: Numbers; NHLS D: Nursing Home Life-Space Diameter; MMSE: Mini-Mental State Examination; PA: Physical activity; PPI: Present Pain Intensity Scale; SD: Standard deviation; SPPB : Short-Physical-Performance-Battery; Short FES-I: Short Falls Efficacy Scale-International, 7-item version; UAB-LSA: University of Alabama at Birmingham - Life-Space Assessment; VRS: Verbal rating scale

\section{Acknowledgements}

We kindly thank Michaela Günther-Lange (Agaplesion Bethanien Hospital, Geriatric Center at the Heidelberg University) and Laura Bauknecht (Medical Faculty of the Heidelberg University) for their assistance in the enrollment and the assessment of participants.

\section{Authors' contributions}

$\mathrm{KH}$ drafted the manuscript. Analyses of the data were carried out by $\mathrm{KH}$ and PU. PU and CW made critical revision of the article. $\mathrm{KH}, \mathrm{JMB}$ and $\mathrm{CW}$ were responsible for the conception of this study and study design. $\mathrm{PH}$ and $\mathrm{SH}$ participated in data collection. All authors read and approved the final manuscript.

\section{Funding}

No specific funding for the secondary data analysis as presented. A doctoral student $(\mathrm{PH})$ which participated in the observation study, on which the present study was based on, was funded by the Robert Bosch foundation and the Network of ageing (NAR) of the Heidelberg University. Funding organizations had no role and influence on the design and conduct of the study; collection, management, analysis, and interpretation of the data; and preparation, review, or approval of the manuscript. Open Access funding enabled and organized by Projekt DEAL.

\section{Availability of data and materials}

Availability was only given to participants (for their own information) and specific members of the study. The datasets generated and/or analysed during the current study are not publicly available as the ethical vote did not include open data access, but are available from the corresponding author on reasonable request.

\section{Ethics approval and consent to participate}

The study was performed according to the Helsinki Declaration and was approved by the ethics committee of the Medical Department of the University of Heidelberg (S-709/2018). Written-informed consent has been part of the mandatory participants' agreement which also included consent to publish data. In case participants would decide to withdraw their consent it was guaranteed that individual data was not used in data analysis and deleted.

Consent for publication

Not applicable.

\section{Competing interests}

The authors declare that they have no competing interests.

\section{Author details}

${ }^{1}$ AGAPLESION Bethanien Hospital Heidelberg/Geriatric Centre of the University of Heidelberg, Rohrbacher Str. 149, 69126 Heidelberg, Germany. ${ }^{2}$ Center of Geriatric Medicine, Heidelberg University, Heidelberg, Germany. ${ }^{3}$ Network Aging Research (NAR), Heidelberg University, Heidelberg, Germany.

${ }^{4}$ Medical Faculty of the Heidelberg University, Heidelberg, Germany.

Received: 4 May 2020 Accepted: 23 November 2020

Published online: 10 December 2020

\section{References}

1. Brown CJ, Redden DT, Flood KL, Allman RM. The underrecognized epidemic of low mobility during hospitalization of older adults. J Am Geriatr Soc. 2009;57(9):1660-5.

2. den Ouden M, Bleijlevens MH, Meijers JM, Zwakhalen SM, Braun SM, Tan FE et al. Daily (in)activities of nursing home residents in their wards: an observation study. J Am Med Dir Assoc. 2015;16(11):963-8.

3. Covinsky KE, Palmer RM, Fortinsky RH, Counsell SR, Stewart AL, Kresevic D, et al. Loss of independence in activities of daily living in older adults hospitalized with medical illnesses: increased vulnerability with age. J Am Geriatr Soc. 2003;51(4):451-8.

4. Kortebein P, Symons TB, Ferrando A, Paddon-Jones D, Ronsen O, Protas E, et al. Functional impact of 10 days of bed rest in healthy older adults. J Gerontol A Biol Sci Med Sci. 2008;63(10):1076-81.

5. Brown CJ, Friedkin RJ, Inouye SK. Prevalence and outcomes of low mobility in hospitalized older patients. J Am Geriatr Soc. 2004;52(8):1263-70.

6. Webber SC, Porter MM, Menec VH. Mobility in older adults: a comprehensive framework. The Gerontologist. 2010;50(4):443-50.

7. Parker M, Baker PS, Allman RM. A life-space approach to functional assessment of mobility in the elderly. J Gerontol Soc Work. 2002;35(4):35-55

8. Taylor JK, Buchan IE, van der Veer SN. Assessing life-space mobility for a more holistic view on wellbeing in geriatric research and clinical practice. Aging Clin Exp Res. 2019;31:439-45.

9. Brown CJ, Williams BR, Woodby LL, Davis LL, Allman RM. Barriers to mobility during hospitalization from the perspectives of older patients and their nurses and physicians. J Hosp Med. 2007;2(5):305-13.

10. Jansen CP, Diegelmann M, Schnabel EL, Wahl HW, Hauer K. Life-space and movement behavior in nursing home residents: results of a new sensorbased assessment and associated factors. BMC Geriatr. 2017;17(1):36.

11. Motzek T, Junge $M$, Marquardt $G$. Impact of dementia on length of stay and costs in acute care hospitals]. [Article in German]. Z Gerontol Geriatr. 2017;50(1):59-66.

12. Pedone C, Ercolani S, Catani M, Maggio D, Ruggiero C, Quartesan R, et al. Elderly patients with cognitive impairment have a high risk for functional decline during hospitalization: the GIFA study. J Gerontol A Biol Sci Med Sci. 2005;60(12):1576-80.

13. Hauer K, Lord SR, Lindemann U, Lamb SE, Aminian K, Schwenk M. Assessment of physical activity in older people with and without cognitive impairment. J Aging Phys Act. 2011;19(4):347-72. 
14. Ullrich P, Werner C, Bongartz M, Kiss R, Bauer J, Hauer K. Validation of a modified life-space assessment in multimorbid older persons with cognitive impairment. The Gerontologist. 2019;59(2):e66-75.

15. Schuler M, Njoo N, Hestermann M, Oster P, Hauer K Acute and chronic pain in geriatrics: clinical characteristics of pain and the influence of cognition. Pain Med. 2004; 5(3):253-62.

16. Baker PS, Bodner EV, Allman RM. Measuring life-space mobility in community-dwelling older adults. J Am Geriatr Soc. 2003;51(11):1610-4.

17. May D, Nayak US, Isaacs B. The life-space diary: a measure of mobility in old people at home. Int Rehabil Med. 1985;7(4):182-6.

18. Stalvey BT, Owsley C, Sloane ME, Ball K. The life space questionnaire: a measure of the extent of mobility of older adults. J Appl Gerontol. 1999; 18(4):460-78.

19. Hashidate H, Shimada H, Shiomi T, Shibata M, Sawada K, Sasamoto N. Measuring indoor life-space mobility at home in older adults with difficulty to perform outdoor activities. J Geriatr Phys Ther. 2013;36(3): 109-14.

20. Tinetti ME, Ginter SF. The nursing home life-space diameter. A measure of extent and frequency of mobility among nursing home residents. J Am Geriatr Soc. 1990;38(12):1311-5.

21. Folstein MF, Folstein SE, McHugh PR. "Mini-mental state". A practical method for grading the cognitive state of patients for the clinician. J Psychiatr Res. 1975;12(3):189-98.

22. Inouye SK, van Dyck CH, Alessi CA, Balkin S, Siegal AP, Horwitz RI. Clarifying confusion: the confusion assessment method. A new method for detection of delirium. Ann Intern Med. 1990;113(12):941-8.

23. Rockwood K, Song X, MacKnight C, Bergman H, Hogan D, McDowell I, et al. A global clinical measure of fitness and frailty in elderly people. CMAJ. 2005; 173(5):489-95.

24. Hauer K, Lamb S, Jorstad E, Todd C, Becker C, PROFANE-Group. Systematic review of definitions and methods of measuring falls in randomised controlled fall prevention trials. Age Ageing. 2006;35(1):5-10.

25. Ferrell BA, Ferrell BR, Rivera L. Pain in cognitively impaired nursing home patients. J Pain Symptom Manage. 1995;10(8):591-8.

26. Rabin R, de Charro F. EQ-5D: a measure of health status from the EuroQol group. Ann Med. 2001;33(5):337-43.

27. Marin RS, Biedrzycki RC, Firinciogullari S. Reliability and validity of the apathy evaluation scale. Psychiatry Res. 1991;38(2):143-62.

28. Hauer K, Kempen Gl, Schwenk M, Yardley L, Beyer N, Todd C, et al. Validity and sensitivity to change of the falls efficacy scales international to assess fear of falling in older adults with and without cognitive impairment. Gerontology. 2011;57(5):462-72.

29. Kempen Gl, Yardley L, van Haastregt JC, Zijlstra GA, Beyer N, Hauer K, et al. The short FES-I: a shortened version of the falls efficacy scale-international to assess fear of falling. Age Ageing. 2008;37(1):45-50.

30. Mahoney FI, Barthel DW. Functional evaluation: the Barthel Index. Md State Med J. 1965;14:61-5

31. Guralnik JM, Simonsick EM, Ferrucci L, Glynn RJ, Berkman LF, Blazer DG, et al. A short physical performance battery assessing lower extremity function: association with self-reported disability and prediction of mortality and nursing home admission. J Gerontol. 1994;49(2):M85-94.

32. Bongartz $M$, Kiss $R$, Lacroix $A$, Eckert $T$, Ullrich $P$, Jansen $C P$, et al. Validity, reliability, and feasibility of the uSense activity monitor to register physical activity and gait performance in habitual settings of geriatric patients. Physiol Meas. 2019;40(9):095005.

33. Bhandari A, Wagner T. Self-reported utilization of health care services: improving measurement and accuracy. Med Care Res Rev. 2006;63(2): 217-35.

34. Shephard RJ. Limits to the measurement of habitual physical activity by questionnaires. Br J Sports Med. 2003;37(3):197-206 discussion.

35. McHorney CA, Tarlov AR. Individual-patient monitoring in clinical practice: are available health status surveys adequate? Qual Life Res. 1995;4(4):293307.

36. Cohen J. Statistical power analysis for the behavioral sciences. 2nd ed. Hillsdale: LAWRENCE ERLBAUM ASSOCIATES; 1988.

37. Fleiss JL. The design and analysis of clinical experiments. New York: Wiley; 1986.

38. Katz JN, Larson MG, Phillips CB, Fossel AH, Liang MH. Comparative measurement sensitivity of short and longer health status instruments. Med Care. 1992:30(10):917-25.
39. Middel B, van Sonderen E. Statistical significant change versus relevant or important change in (quasi) experimental design: some conceptual and methodological problems in estimating magnitude of intervention-related change in health services research. Int J Integr Care. 2002;2:e15.

40. Gell NM, Wallace RB, LaCroix AZ, Mroz TM, Patel KV. Mobility device use in older adults and incidence of falls and worry about falling: findings from the 2011-2012 national health and aging trends study. J Am Geriatr Soc. 2015;63(5):853-9.

41. Sallis JF, Saelens BE. Assessment of physical activity by self-report: status, limitations, and future directions. Res Q Exerc Sport. 2000;71(2 Suppl):S1-14.

\section{Publisher's Note}

Springer Nature remains neutral with regard to jurisdictional claims in published maps and institutional affiliations.
Ready to submit your research? Choose BMC and benefit from:

- fast, convenient online submission

- thorough peer review by experienced researchers in your field

- rapid publication on acceptance

- support for research data, including large and complex data types

- gold Open Access which fosters wider collaboration and increased citations

- maximum visibility for your research: over $100 \mathrm{M}$ website views per year

At BMC, research is always in progress.

Learn more biomedcentral.com/submissions 